Document downloaded from:

http://hdl.handle.net/10251/113828

This paper must be cited as:

Micó Vicent, B.; López, M.; Bello, A.; Martínez, N.; Martínez Verdú, F. (2017). Optimum multilayer-Graphene-Montmorillonite Composites from sugar for thermosolar coatings formulations. Journal of Solar Energy Engineering. 139(3):1-7. doi:10.1115/1.4035757

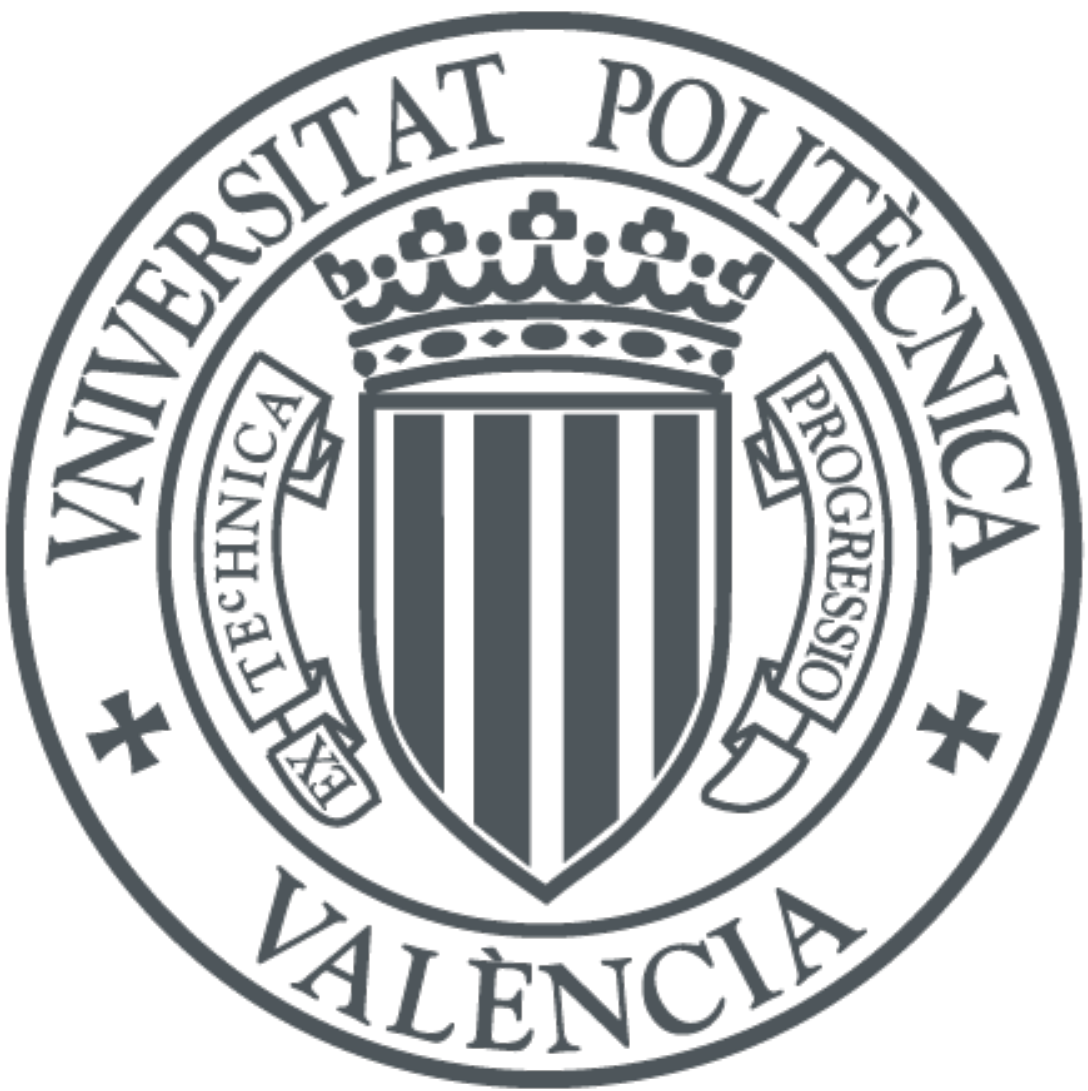

The final publication is available at

http://doi.org/10.1115/1.4035757

Copyright ASME International

Additional Information 


\title{
Optimum multilayer-graphene- montmorillonite composites from sugar for thermosolar coatings formulations
}

\author{
Bàrbara Micó-Vicent, first author ${ }^{1}$ \\ Colour and Vision Group, University of Alicante \\ Carretera de San Vicent, S/N, 03690, Spain \\ Departamento de Estadística e Investigación Operativas Aplicadas y Calidad, Universitat \\ Politècnica de València (UPV) \\ Plaza Ferrandiz y Carbonell 1, 03801, Alcoy, Alicante, Spain \\ Barbara.mico@ua.es \\ ASME Membership (if applicable)
}

María López, second author

ABENGOA RESEARCH

Edificio Solandcenter, Carretera A-472, P.K. 5,85, margen derecha. 41800, Sanlúcar la

Mayor, Seville, Spain

maria.herraiz@abengoa.com

ASME Membership (if applicable)

Azucena Bello, third author

ABENGOA RESEARCH

Edificio Solandcenter, Carretera A-472, P.K. 5,85, margen derecha. 41800, Sanlúcar la

Mayor, Seville, Spain

bf.azucena@gmail.com

ASME Membership (if applicable)

\author{
Noelia Martínez, fourth author \\ ABENGOA RESEARCH \\ Universidad Rey Juan Carlos \\ Paseo de la Castellana, 43. 28046 Madrid (Spain) \\ noelia.martinez@abengoa.com \\ ASME Membership (if applicable) \\ Francisco Martínez-Verdú, sixth author \\ Colour and Vision Group, University of Alicante \\ Carretera de San Vicent, S/N, 03690, Alicante Spain \\ verdu@ua.es \\ ASME Membership (if applicable)
}

\footnotetext{
${ }^{1}$ Corresponding author information can be added as a footnote.
} 
Journal of Solar Energy Engineering

\section{ABSTRACT}

Solar thermal coatings are designed to achieve the highest incident solar flux into the receiver of a tower solar plant. These materials are subjected to extreme working conditions of temperature and solar concentrated radiation. Much effort is being made to develop a durable and high absorptive coating that can provide excellent solar to heat conversion efficiency. Complex deposition techniques (PVD, CVD, electrodeposition, etc.) are developed and tested to achieve solar selectivity. High solar absorptance paints are an alternative technique that is easy to apply and implement in the field. In paint, pigments are the compound that provides high absorptance values, whose stability impacts the durability of optical properties.

The search for new selective solar pigments for solar receivers is a promising route to improve the efficiency of this technology. In this work, novel nanocomposites were synthesized from low-cost organic materials as table sugar. Promising results were obtained when intercalated and calcined in the laminar structure of montmorillonite, a type of smectite clay. Pigments were tested in a paint format on metallic coupons at different temperatures to obtain absorptivities above $96 \%$ of absorptance after $24 \mathrm{~h}$ at 700 으. Further experiments are still needed to obtain optimum conditions to maximize the coating's absorptivity and durability at high temperature. 


\section{INTRODUCTION}

In recent years, considerable attention has been paid and efforts made in clean energy utilization terms. Among all the possible sources, solar energy is believed one of the most promising technologies of this century. A concentrating solar power (CSP) system plays an important role in solar thermal technology [1]. With more and more industrial systems running successfully, this form of power generation has attracted plenty of attention worldwide [2].

Solar power towers generate electricity from sunlight by focusing solar radiation on the receiver through slightly curved heliostats. Highly solar absorptive surfaces are considered a critical component to convert sunlight into thermal-electrical power. Greater thermal efficiency means more power generation, which will cut average costs and improve the competitiveness of this technology.

The elements that influence the receiver's thermal performance are, apart from the receiver's area, surface absorptivity and emissivity, and number of absorber tubes and their diameter. All the parameters were carefully studied and optimized to obtain the best system performance. Pyromark-2500, a high solar absorptive paint, is generally applied to the metallic surface of receiver tubes. The aforementioned coating has two main drawbacks: its high emissivity and low durability under working conditions [3, 4]. Many different alternatives are being developed to obtain a solar selective (high absorptivity and low emissivity) coating with better durability. Sophisticated techniques, such as PVD, CVD, electrodeposition and many more, are being used to obtain innovative absorbent coatings. Promising results are being obtained with black nickel, 
black copper or black chrome, which are highly stable metallic oxides at high temperature [5].

Given the scope of obtaining low-cost and enviro-friendly solar absorptive pigments that could raise energy efficiency, stable clays at high temperature were studied herein. These pigments can be applied to the tube metallic substrate in a paint format, which could be easily repaired, if necessary, to provide the required optical properties [6].

Montmorillonite microstructure changes during thermal treatment processes have been previously studied, as have their lamellar crystalline structure to disordered phases. Alteration of hydroxyl groups depends mostly on the makeup of octahedral positive ions and mineral crystallization. The non crystalline phase is obtained when heat treatment goes above $700^{\circ} \mathrm{C}$ [7]. To obtain high advanced resistant montmorillonite, different nanoclay modifiers have been used as $\mathrm{OH}-\mathrm{Al}$ polymers [8], as have polyhedral oligomeric silsesquioxane polymers (POSS) $[9,10]$ or sugar carbon precursors. In all these studies, the diffraction peaks of montmorillonite, which corresponds to the basal space, remain in high temperature vacuum treatments.

Montmorillonite clay was selected for its layer structure and it plays the template role in ghaphene-carbone composites. The templating role of the clay substrate during carbonaceous layer growth was checked. It showed limited graphene packing, accompanied by improved surface areas. The thermal analysis and XRD results also indicated the enhanced thermal stability of clay-carbon composites with the mineral preserving its layered structure even at $900^{\circ} \mathrm{C}$. We wished to take advantage of 
montmorillonite stabilization by carbon structures (with the sugar precursor), and also of the thermal conductivity of the preferred ordered carbon structures [11].

The POSS dispersant used in solar coatings has been demonstrated to enhance spectral selectivity. POSS-based nanocomposites were synthesized by simultaneously possessing chemical reactivity and low surface energy, and were applied as dispersants to make pigment dispersions and to achieve self-cleaning properties of black coatings, expressed by their hydrophobicity and oleophobicity [10].

In this work, cetylpyridinium bromide (CPB) and POSS were selected as surface modifiers for the montmorillonite structure given their previous success at opening the nanoclay structure. The basal space of nanoclay increased in both cases. The layer spacing of POSS-modified clay increased from $1.68 \mathrm{~nm}$ to $3.74 \mathrm{~nm}$. Previous works have found temperature reinforcement when using POSS-Montmorillonite with polymer nanocomposites, and a nanocomposite with 10 mass $\%$ clay showed a $61 \%$ reduction in gas permeability [12]. Therefore, we expected to not only achieve nanoclay exfoliation, but also to improve both the contact of nanoclay/sugar molecules and the fastness properties of coatings [13].

Intercalation and ion exchange properties of smectites provide easy routes for combining different carbon-precursors to acquire hybrid carbon-smectite composites. Depending on the working conditions, the mineral carbon phase, the multilayer, or even graphene, a monolayer can be obtained using nanoclays as layered templates. These hybrid carbon materials have a large superficial area and present adsorbing properties that are usually employed in catalytic processes and wastewater treatments [14-17]. 
In this work, we synthesized hybrid montmorillonite-carbon composites from natural source (sugar) in order to use the resulting composite as a black pigment for high solar absorptive coatings. Design of experiments was formulated to select the natural carbon precursor content and the best combination of nanoclay modifiers. Promising results with high stability at working temperatures were obtained with the proposed method.

\section{EXPERIMENTAL}

\section{Materials}

Cationic exchange capacity montmorillonite (M) from Rockwood additives was used. Surfactant cetylpyridinuim bromide hydrate (98\%) (CPB) and PSS-trisilanol-isooctyl substituted (POSS) CAS: 44619-08-3 were employed as the nanoclay modifiers. To adjust $\mathrm{pH}$ during the synthesis process, $\mathrm{HCl}$ - (from Sigma Aldrich) was added to the mixture. Common commercial table sugar was used as the carbon source to manufacture multilayer-graphene-montmorillonite composites (GMC). Metallic substrates (Haynes$617 ; 5 \times 5 \mathrm{~cm}$ ) were previously sandblasted and cleaned with ethanol before applying the developed coating.

\section{Synthesis Method}

Montmorillonite clay was initially dispersed at $1500 \mathrm{rpm}$ for $24 \mathrm{~h}$ in distilled water at $30 \mathrm{~g} / \mathrm{L}$. Two nanoclay modifiers were used: CPB at $10 \%$ and POSS at $5 \%$ on the nanoclay mass. Both modifiers were added before sugar solutions. The stirring process was run in two steps: $1 \mathrm{~h}$ at $1500 \mathrm{rpm}$ and $4 \mathrm{~h}$ at $400 \mathrm{rpm}$. Three different sugarnanoclay ratios were used: $2: 1,1: 1$ and $0.5: 1$. Sugar intercalation was performed in two 
steps, first stirring $1 \mathrm{~h}$ at $1500 \mathrm{rpm}$ at room temperature and then $24 \mathrm{~h}$ at $600 \mathrm{rpm}$. Next samples were centrifuged to remove the remaining water, which produced the nanocomposite material in a paste form. This paste was redispersed at $400 \mathrm{rpm}$ for 30 minutes to remove any possible trace of sugar and any excess acid. The washing process was run 3 times. The paste nanocomposite was dried at $90^{\circ} \mathrm{C}$ for $24 \mathrm{~h}$ in an oven to obtain nanocomposite powder. Finally, the carbon-intercalated structure was obtained by a calcination process in a heating muffle at $800^{\circ} \mathrm{C}$ for $3 \mathrm{~h}$ in an oxidant atmosphere.

\section{Design of Experiments (DoE)}

A factorial 32 design of experiments was employed to compare the concentration sugar factor and modifier presence or mixture. The sugar-clay ratio was: (1)-2:1, (2)-1:1, (3)-0.5:1. Modifier levels were: (1)-CPB, (2)-POSS, and (3)-CPB and POSS together (Table 1).

Table 1. DoE $3^{2}$ for the evaluation of montmorillonite pigment properties depending on sugar concentration and presence of modifiers

\begin{tabular}{lccc}
\hline Code & Experiment & Sugar & Modifier \\
\hline C1_1 & 1 & 2 & 1 \\
C1_2 & 2 & 1 & 3 \\
C1_3 & 3 & 3 & 2 \\
C1_4 & 4 & 2 & 2 \\
C1_5 & 5 & 3 & 3 \\
C1_6 & 6 & 1 & 2 \\
C1_7 & 7 & 2 & 3 \\
C1_8 & 8 & 1 & 1 \\
C1_9 & 9 & 3 & 1 \\
\hline
\end{tabular}




\section{Thermal tests}

Once synthesized, the powder was mixed at $30 \% \mathrm{w}$ with a commercial binder to test them in a paint format. Each coating was applied to three substrates to study its reproducibility during the thermal tests (Fig. 1). The thermal stability of the coatings was evaluated at two different temperatures $\left(600^{\circ} \mathrm{C}\right.$ and $\left.700^{\circ} \mathrm{C}\right)$ after $24 \mathrm{~h}$ in a furnace in an oxidant atmosphere.

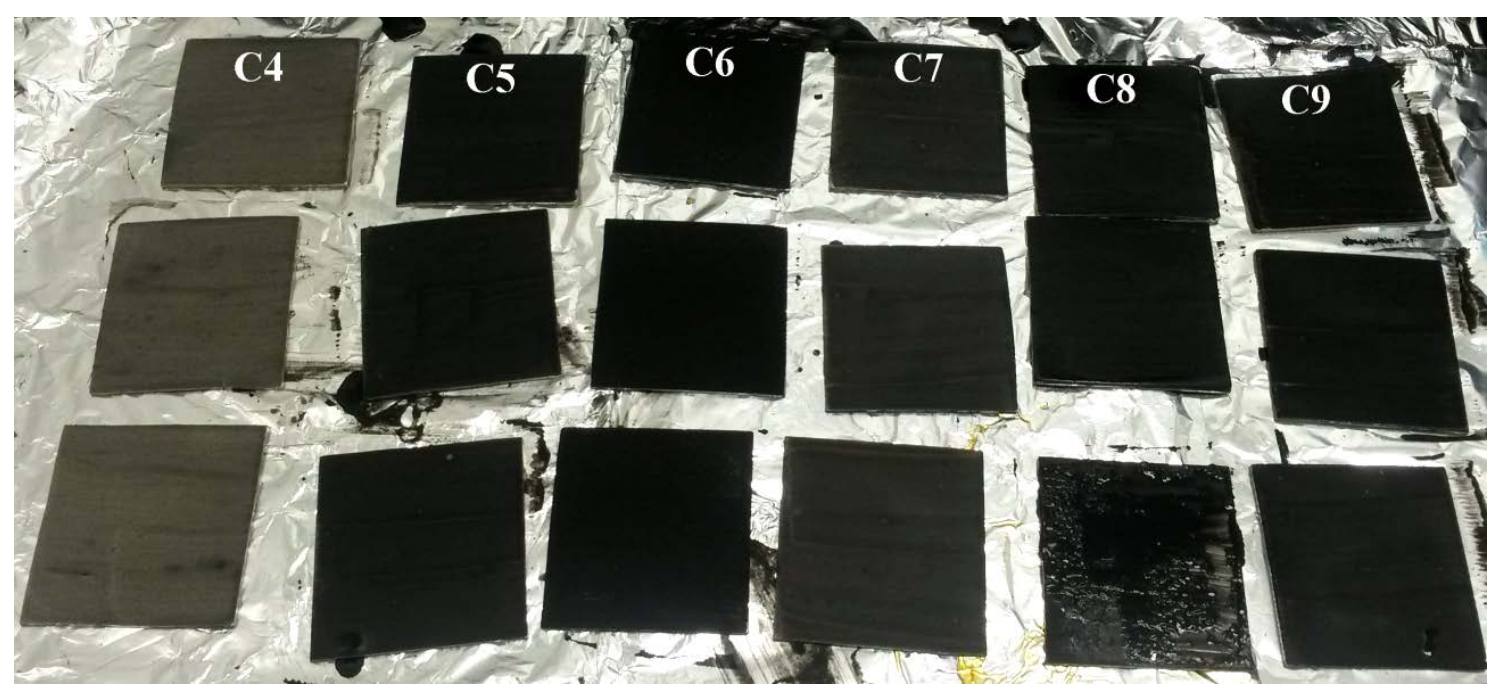

Fig. 1. The initial coating samples prepared from synthesized pigments

\section{Characterization techniques}

Different characterization techniques were followed to evaluate the black coating properties from synthesized pigments.

Optical characterization was made using two different devices. For the UV to NIR measurements, the Lambda-1050 UV/Vis spectrometer (Perkin Elmer WinLab software) was used, which comes with an integrating sphere attachment to measure reflectance. Absorptance is calculated by measuring the near UV, visible and IR from $300 \mathrm{~nm}$ to 2500 
$\mathrm{nm}$. With this spectrometer, scans are run at a resolution of $10 \mathrm{~nm}$ increments, with a monocromator change at $860.8 \mathrm{~nm}$ and a lamp change at $319.20 \mathrm{~nm}$.

IR reflectance measurements were taken with an FTIR-Vertex 70 from 500 to $7000 \mathrm{~cm}-1$ using an integrating sphere (Bruker A562) at a resolution of $15 \mathrm{~cm}-1$. It was calibrated with a gold coupon measured as a reference. The beam impinged on the sample at an incident angle of 13‥ The diffuse and specular reflected part of light was detected by a detector located behind the outlet port.

To control the montmorillonite structure changes after heat treatments, a DRX Bruker D8-Advance equipment, with a Göebel mirror (Potency: 3000W, Tension: 20$60 \mathrm{KV}$ and Current intensity: 5-80mA), was used. Measurements were taken in an oxidant atmosphere at an angular speed of $1 \% / \mathrm{min}$, STEP 0.050 and an angular scan of [2.7-70]‥ A JEOL JEM-2010 transmission electron microscope was used for the morphological analysis. Images were acquired with a GATAN ORIUS SC600 digital camera mounted on-axis, and integrated with the GATAN DigitalMicrograph program, 1.80.70 for GMS 1.8.0. Graphene phase characterization and mineral carbon presence were detected by a vibrational Raman spectroscopy with an $\operatorname{Ar}(514 \mathrm{~nm})$ laser in a dispersive model (LabRam; Jobin-Ivon).

\section{RESULTS AND DISCUSSION}

All the samples in Table 2, except C1_4, obtained absorptivities that exceeded 90\%, while C1_1, C1_5, C1_6 and C1_8 achieved absorptivities above 95\%. After the heat treatment tests, sample absorptivity decreased in all cases, but not in the same 
proportion. Some of the samples still had absorptivities higher than $95 \%$ after the $48-$

hour tests; e.g., C1_6. There were notable differences in emittance among all the synthesized samples. The statistical parameters from the DoE responses were evaluated to study the possible factors that affected these differences.

Table 2. Absorptance $(\alpha \%)$ and emittance $(\varepsilon \%)$ of the initial synthesized coatings samples and after the thermal tests.

\begin{tabular}{ccccccc}
\hline & \multicolumn{3}{c}{ Initial values } & \multicolumn{2}{c}{$24 \mathrm{~h} 600 \circ \mathrm{C}$} & \multicolumn{2}{c}{$24 \mathrm{~h} \mathrm{700 \circ \textrm {C }}$} \\
\hline Sample & $\alpha \%$ & $\varepsilon(700 \circ \mathrm{C}) \%$ & $\alpha \%$ & $\varepsilon(700 \circ \mathrm{C}) \%$ & $\alpha \%$ & $\varepsilon(700 \circ \mathrm{C}) \%$ \\
\hline C1_1 & 96.12 & 96.93 & 90.50 & 92.60 & 85.98 & 89.00 \\
C1_2 & 93.41 & 95.70 & 82.43 & 88.70 & 80.75 & 85.70 \\
C1_3 & 93.79 & 94.60 & 91.45 & 90.30 & 88.97 & 90.70 \\
C1_4 & 82.94 & 91.13 & 77.61 & 87.90 & - & - \\
C1_5 & 95.09 & 95.03 & 92.38 & 91.90 & 90.76 & 90.00 \\
C1_6 & 97.72 & 97.50 & 96.52 & 96.20 & 96.28 & 96.10 \\
C1_7 & 90.58 & 93.90 & 86.46 & 89.10 & 84.75 & 88.50 \\
C1_8 & 96.92 & 96.70 & 95.11 & 93.60 & 92.70 & 93.80 \\
C1_9 & 94.92 & 95.03 & 87.11 & 89.50 & - & - \\
\hline
\end{tabular}

- No available result because of prolems with handling samples

Table 3. Analysis of variance (ANOVA) to maximize the initial absorbance response $\alpha \%$ using three experiment replications (BLOCK)

\begin{tabular}{cccccc}
\hline Principal effects & $\begin{array}{c}\text { Sum of } \\
\text { Squares }\end{array}$ & $g^{l^{a}}$ & $\begin{array}{c}\text { Mean } \\
\text { Square }\end{array}$ & F-rate & $P$-value \\
\hline A: BLOCK & 0.308363 & 2 & 0.154181 & 1.72 & 0.2399 \\
B:SUGAR & 185.49 & 2 & 92.745 & 1031.89 & 0.0000 \\
C:MODIFIER & 93.653 & 2 & 46.8265 & 521 & 0.0000 \\
\hline Interactions & & & & & \\
\hline AB & 0.574926 & 4 & 0.143731 & 1.60 & 0.2648 \\
AC & 1.64975 & 4 & 0.412437 & 4.59 & 0.0321 \\
BC & 203.515 & 4 & 50.8789 & 566.08 & 0.0000 \\
RESIDUE & 0.71903 & 8 & 0.0898787 & & \\
TOTAL & 485.911 & 26 & & & \\
\hline a degrees of freedom & & & &
\end{tabular}


The analysis of variance indicated that the selected factors were statistically significant, as were their interactions $(B C)$ in the absorbance response. Experimental replication (BLOCK) differences were not significant (a P-value higher than 0.05). Hence the reproducibility result is good (Table 3).

By means of a plot analysis, the best level was 1 for Sugar (2:1) and 1 for the modifier factors (CPB) optimized for initial absorptivity. The sugar concentration did not have a linear tendency with the Abs\% response. The worst result was obtained with the same sugar-clay ratio (1:1). CPB was the best modifier and POSS alone led to the worst response (Fig.2).
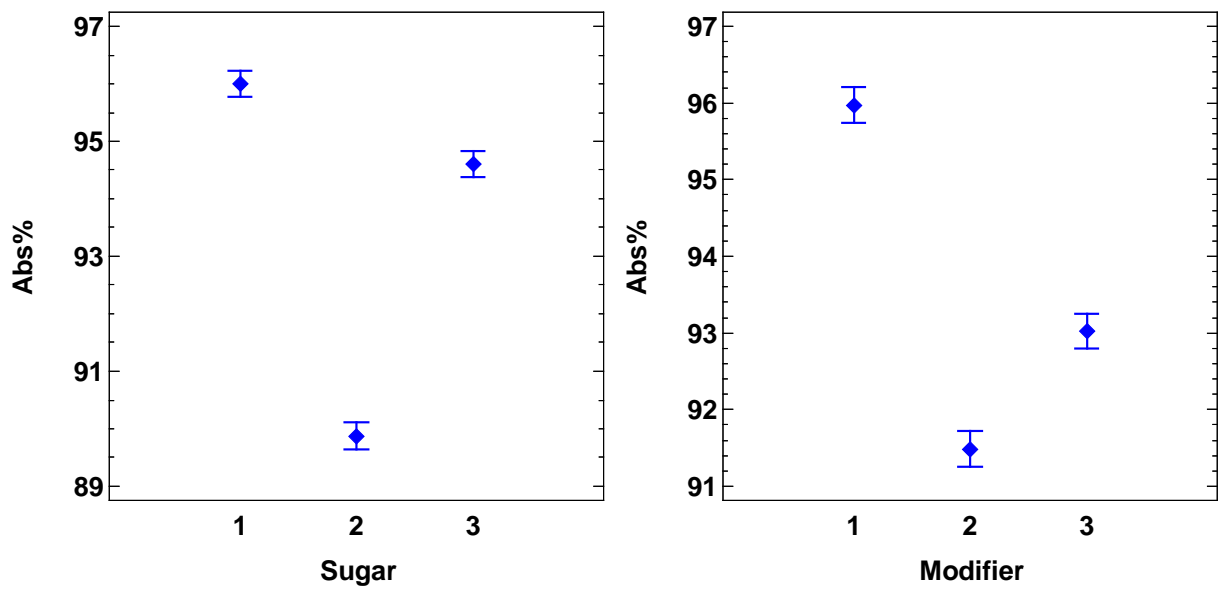

Fig. 2. Means plot for the absorbance response (Abs\%) with sugar levels; (1)-2:1, (2)1:1, (3)-0.5:1 (left) and with modifier levels: 1-CPB, 2-POSS, and 3-CPB and POSS together (right)

Using a second surfactant to improve POSS-montmorillonite intercalation was purposed in 2009. Researchers have found that the interlayer space of POSS-modified clay (POSSMMT) depends strongly on the POSS surfactant arrangement, but less on the POSS concentration. The sodium ions in Na-MMT were only partially exchanged by protonized POSS due to the steric hindrance effect. The dual-surfactant-modified clays exhibited 
increased exchange ratios by controlling the amount of the second surfactant, which resulted in a good hydrophobicity-polarity balance for the modified clays [18]. Without the CPB intercalation, POSS was unable to intercalate on the basal space of montmorillonite. We thought that the optimal results would be obtained with both modifiers (Fig. 3), but only CPB had to be used for the Abs\% response.

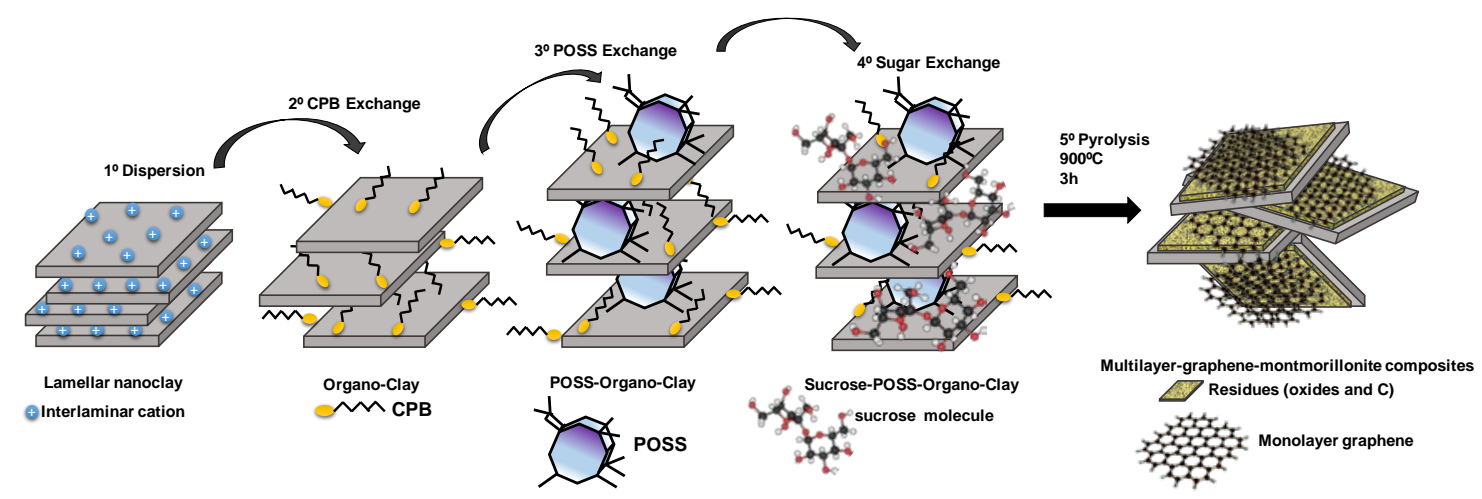

Fig. 3. Composite material designed as an ideal black pigment production scheme with the selected raw materials. Interactions between factors were significant, as expected, and as seen in the interactions plot. Figure 3 shows that with the same sugar and montmorillonite concentration, POSS was the worst combination to obtain the maximum Abs\% value. When CPB was used, the sugar concentration effect displayed a linear tendency. Therefore, the best result was obtained at the highest sugar concentration. Further tests were run with even higher sugar-clay ratios (3:1), but no significant improvement was found. When mixing POSS and CPB, the sugar concentration effect was the same as the POSS effect.

The interaction analysis was run after the two thermal tests were also carried out. At $600{ }^{\circ} \mathrm{C}$ (Fig. 4), the maximum absorption result was obtained with POSS and a 2:1 (sugar:nanoclay) concentration. The sugar content effect was not linear with the POSS 
modifier. The worst combination was obtained with the same nanoclay-sugar content.

When using CPB, variation in absorptivity versus sugar content was linear. The tendency results after using a mixture of CPB and POSS were the exact opposite. The best result was obtained at the lowest sugar concentration because of the substitution competition between modifiers and the sucrose molecule.
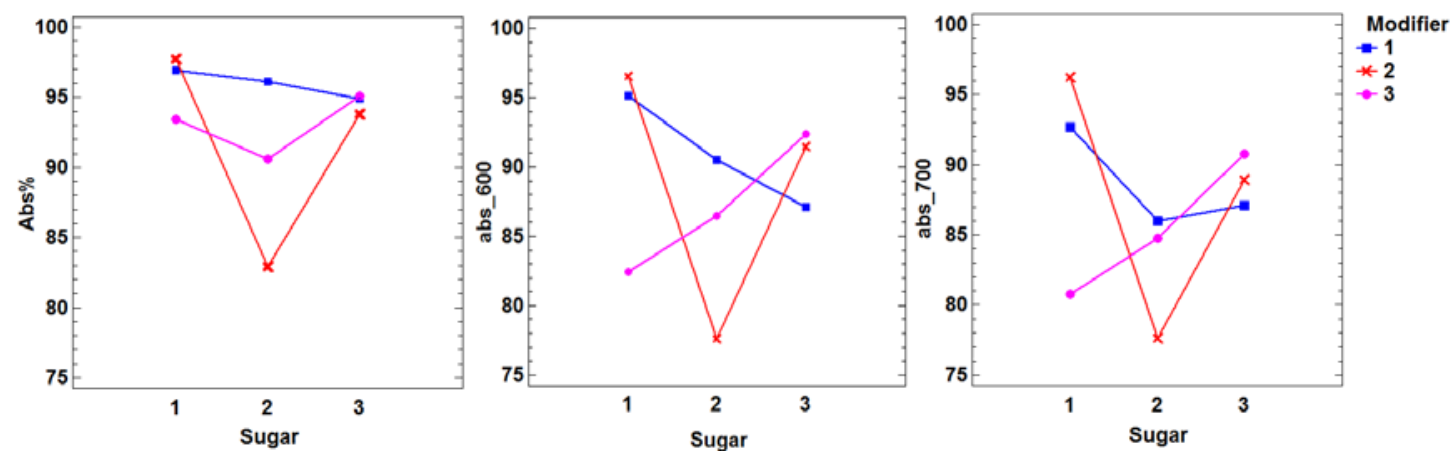

Fig. 4. Interactions plot for the initial absorptivity response (left), after $24 \mathrm{~h}$ at $600 \circ \mathrm{C}$ (center) and after $24 \mathrm{~h}$ at $700 \circ \mathrm{C}$ (right). Sugar concentration ratio: (1)-2:1, (2)1:1, (3)-0.5:1. Modifier levels: (1)-CPB, (2)-POSS, and (3)-CPB and POSS together After running the hardest test conditions $\left(700^{\circ} \mathrm{C}\right)$, interaction tendencies slightly changed. When using CPB, variation in absorptivity was not linear with sugar content. The best result was once again obtained with the maximum sugar content. The maximum absorptivity response was obtained with POSS and a 2:1 sugar-nanoclay ratio. This result was similar to that obtained for the same sample after the thermal test run at $600^{\circ} \mathrm{C}$. When using the CPB modifier mixed with POSS, absorptivity decreased when the sugar content of the pigment increased. Once again at a high concentration and with both modifiers, sucrose molecules easily interacted with the montmorillonite surface, instead of the basal spacing. This avoided the preferred ordered multilayer graphene formation. The result was the disordered carbon generation outside the lamellar structure with no heat fastness. 
Another important analyzed characteristic was adherence to metallic substrates.

The scratch-proof test was done according to standard ISO 1518-1 indications. Scale factors varied from $0-5$, with the best adherence at 0 . This test was performed with the initial samples and the thermally tested samples at $600^{\circ} \mathrm{C}$ and $700^{\circ} \mathrm{C}$. The best adherence was achieved in sample C1_3. The influencing factors were studied by analyzing the DoE results (Table 4).

Table 4. Adherence results from the Scratch-proof of the initial samples and after the thermal tests.

\begin{tabular}{cccc}
\hline Sample & Initial & 24 h 600C & 24 h 700C \\
\hline C1_1 & 0 & 0 & 1 \\
C1_2 & 0 & 0 & 1 \\
C1_3 & 0 & 0 & 0 \\
C1_4 & 1 & 3 & 0 \\
C1_5 & 0 & 0 & 1 \\
C1_6 & 0 & 0.5 & 1 \\
C1_7 & 1 & 0 & 0 \\
C1_8 & - & 1 & 1 \\
C1_9 & 3 & 0 & 0 \\
\hline
\end{tabular}

At $600^{\circ} \mathrm{C}$, the lowest scratch-proof value was given for the lowest sugar content.

This result did not depend on the employed modifier. When using POSS (C1_3, C1_4 and C1_6), the worst effect was obtained with the same sugar and nanoclay content. At the maximum sugar content, the POSS-CPB combination was the best choice, followed by using modifiers POSS and CPB individually. In this case, the theoretical optimal structure was correct (Fig. 3). The modifier interactions and maximum sucrose concentrations led to the maximum superficial area for coating adhesion to the substrate. Under these conditions, the disordered carbon formation on the generated composite material helped enhance the coating-metal subtract contact. 
At $700^{\circ} \mathrm{C}$, the results proved better than those obtained at $600 \circ \mathrm{C}$, which indicated improved adherence. When using the CPB and POSS modifiers combination, the best result was obtained with the same sugar-nanoclay content (Fig. 5).
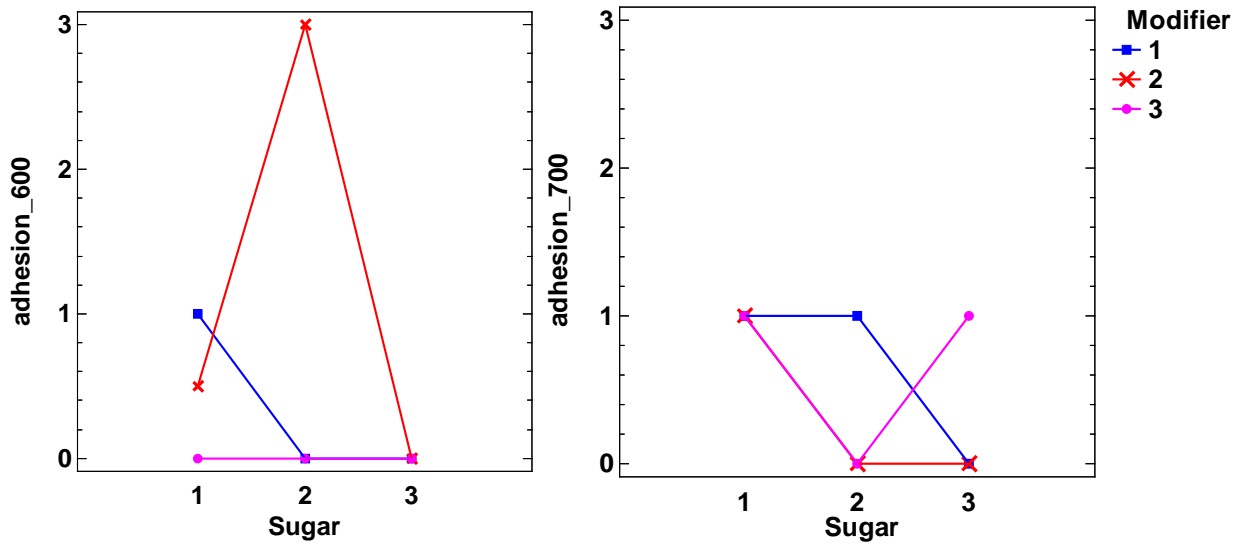

Fig. 5. Interactions plot for the adhesion response after $24 \mathrm{~h}$ at $600^{\circ} \mathrm{C}$ (left) and after $24 \mathrm{~h}$ at $700 \circ \mathrm{C}$ (right). Sugar levels: (1)-2:1, (2)-1:1, (3)-0.5:1. Modifier levels: (1)CPB, (2)-POSS, and (3)-CPB and POSS together.

Table 5. DoE results balance for the absorption and adherence GMC properties

\begin{tabular}{ccc}
\hline & Sugar & Modifier \\
\hline$\alpha(\%)$ & $1-2$ & 1 \\
$\alpha$ at $600 \circ \mathrm{C}(\%)$ & $1-2$ & $1-2$ \\
$\alpha$ at $700^{\circ} \mathrm{C}(\%)$ & 1 & $1-2$ \\
$\begin{array}{c}\text { Adherence at } \\
\text { 600ㄷ }\end{array}$ & 1 & 3 \\
Adherence at & & \\
$700 \circ \mathrm{C}$ & 2 & 3 \\
Balance & $\mathbf{1}$ & $\mathbf{1}$ \\
\hline
\end{tabular}

Finally, an overall analysis was run with all the DoE results to obtain the best

factor combination. This led to the best GMC-pigment properties. Maximum absorptivity and good adherence results are guaranteed when using the maximum sugar content (2:1) and CPB as a modifier, regardless of the test temperature (Table 5). However when tested at $700^{\circ} \mathrm{C}$, the best absorptivity value was obtained with the POSS 
modifier. For these reasons, none of the modifiers was ruled out and the pigments selected for further optimization experiments were C1_6 and C1_8, which were the best candidates (CPB or POSS modifiers with maximum sugar content).

\section{TEM}

The TEM images of each sample were analyzed to study the GMC structure characteristics. As we can see in selected samples $\mathrm{C} 1 \_6$ and $\mathrm{C} 1 \_8$, laminar pattern were found after heat treatment.

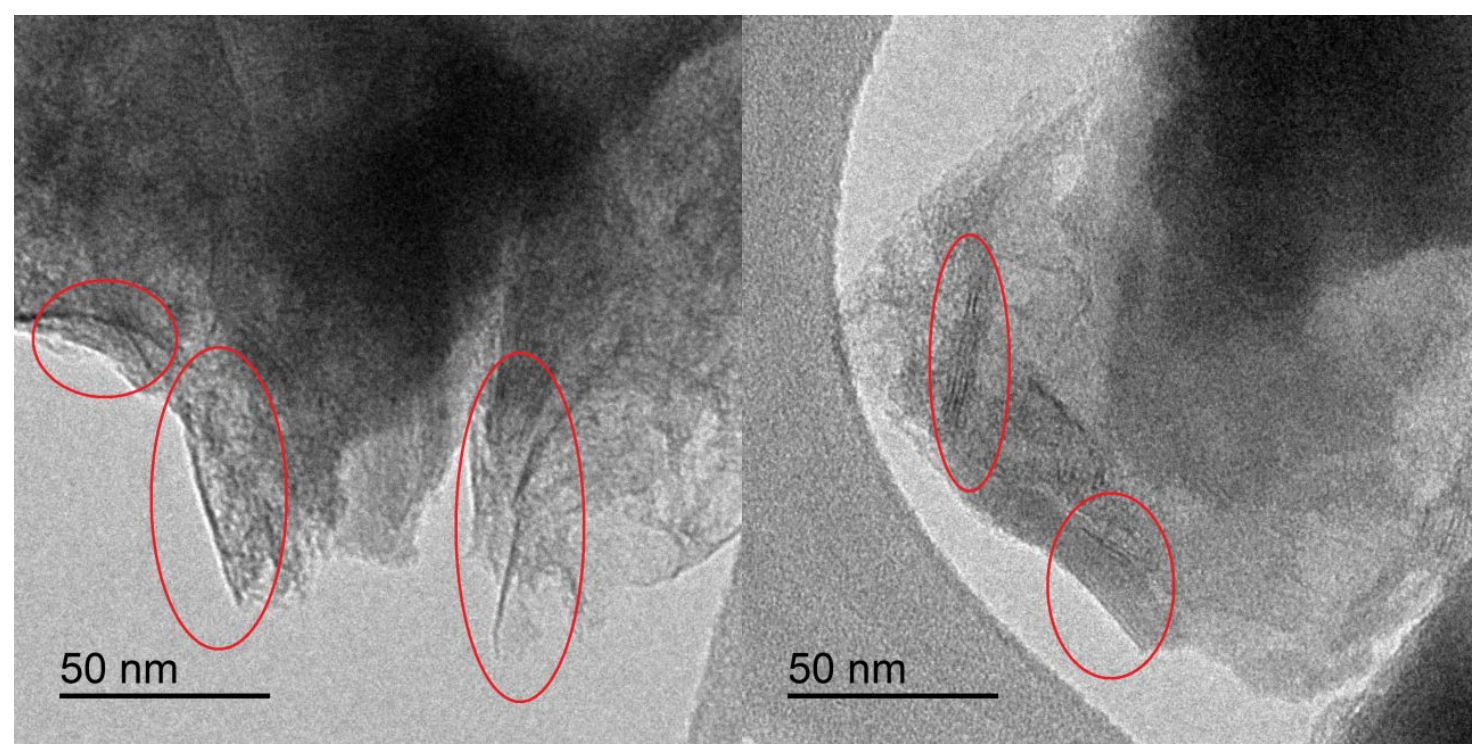

Fig. 6. The TEM images for samples C1_6 (left) and C1_8 (right)

This structure could be due to two facts: the montmorillonite structure remained intact after the calcination process, or edges of graphene layers were forming (Fig. 6). Further analyses are needed to corroborate these hypotheses.

\section{DRX}

Despite the modifiers and the intercalation of sugar into the clay structure, no diffraction pattern of the initial montmorillonite were found. After comparing this process with previous works, the calcination step was performed for $3 \mathrm{~h}$ in an oxidant 
atmosphere. Under these conditions, the laminar montmorillonite structure did not remain [11]. However, the diffraction peaks that corresponded to $4.10 \AA$ and $3.44 \AA$ were attributed to the dispositions of graphene layers [20], but the $3.44 \AA$ peak could also be attributed to the crystalline modification of the original montmorillonite (Fig. 7). Carbon phase formation must be checked by other analysis techniques, like Raman spectroscopy.

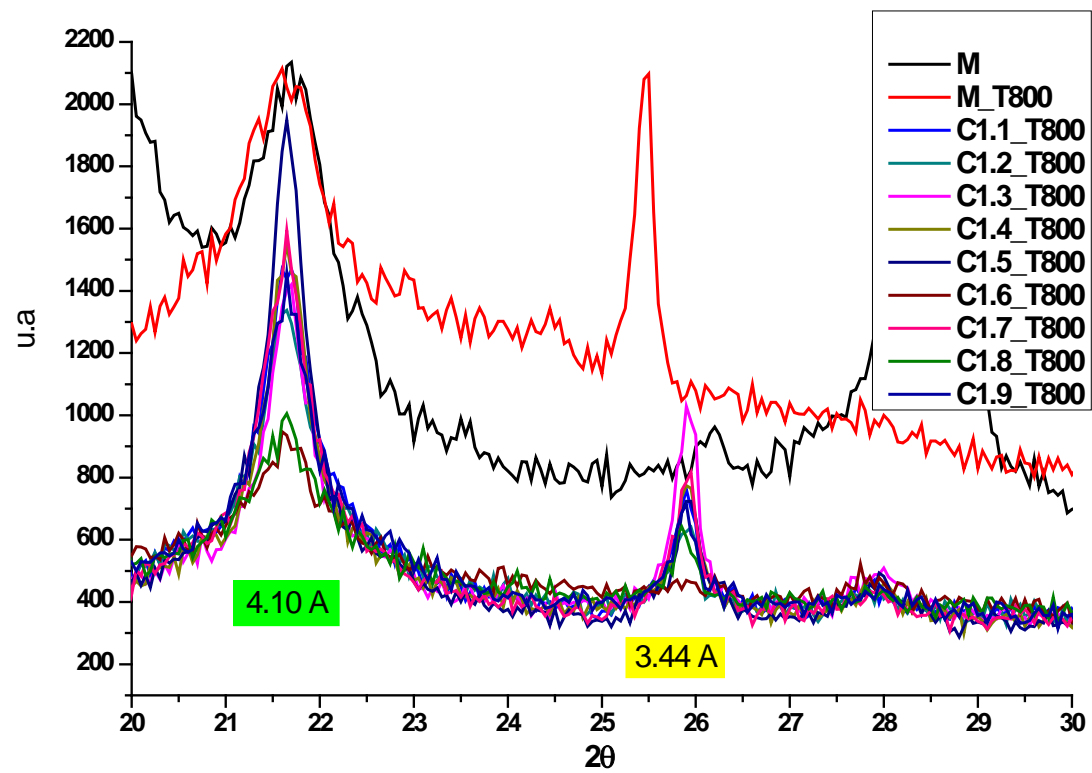

Fig. 7. The X-ray diffraction pattern of the GMC samples under the different synthesis conditions, and the original montmorillonite (M), and calcined montmorillonite (M_T800)

To obtain the finger print of graphene layers and to characterize it, a Raman shift analysis was performed. As seen in the selected example, with the same sugar-nanoclay content $(\mathrm{MAz}(1: 1))(\mathrm{Fig} .8)$ the peaks corresponded to mineral carbon and multilayer graphene [21-22]. If mono- or bilayer graphene without mineral carbon is desired, samples can be treated with $\mathrm{HCl}$ - and $\mathrm{HF}$ after pyrolysis to obtain a pure carbon phase [23]. However in view of the results, the multilayer graphene layers obtained in the 
montmorillonite composites gave excellent adherence and absorptivity values that can be used as a high absorptive solar coating.

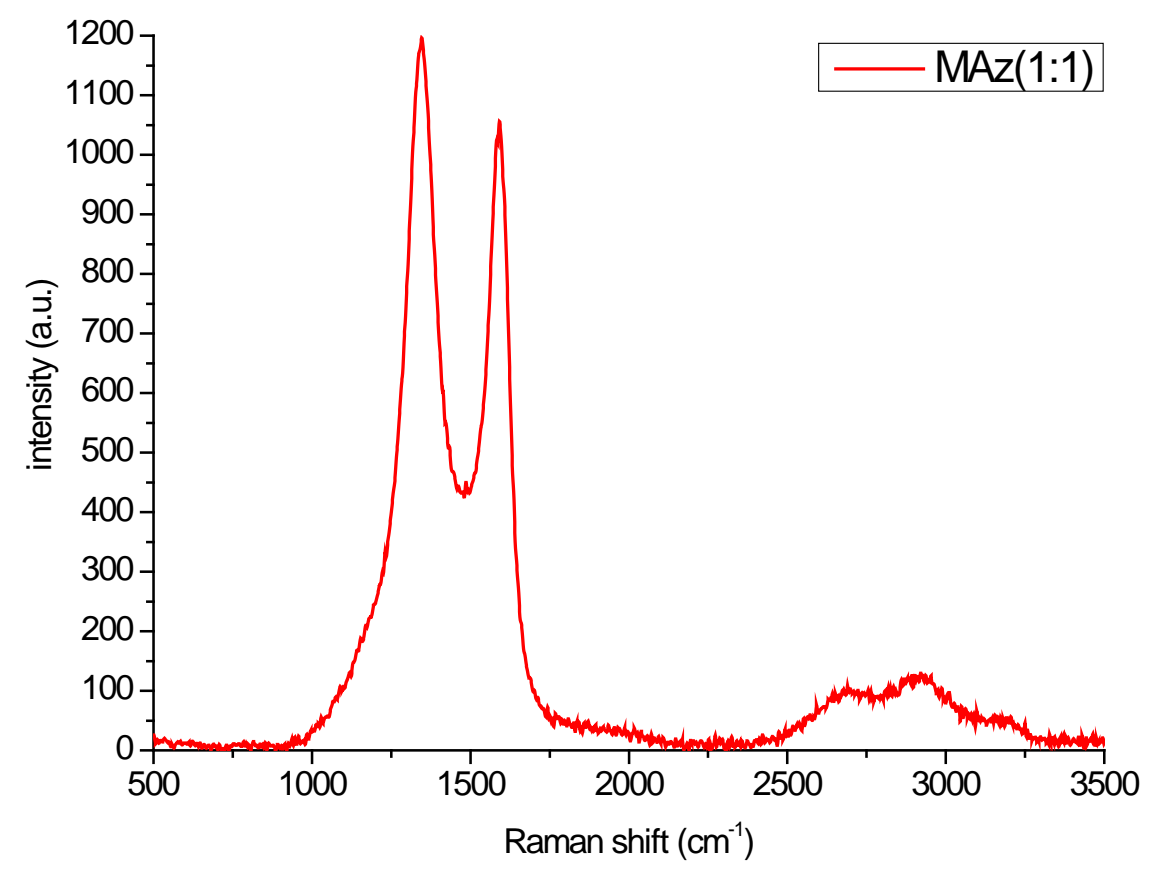

Fig. 8. Raman shift for the same sugar-nanoclay content during the synthesis process $\operatorname{MAz}(1: 1)$

\section{CONCLUSIONS}

Multilayer GMC were obtained using common sugar at different concentrations and in various combinations of CPB and POSS modifiers. The best absorptance value and adhesion results were obtained with the maximum sugar-to-clay ratio content $(2: 1)$, and with individual additions of modifiers (CPB or POSS, but not mixed). All the samples presented good adherence, even after $24 \mathrm{~h}$ at $700^{\circ} \mathrm{C}$.

A new crystalline structure was formed after the intercalation and calcination of sugar in the montmorillonite structure. The Raman analysis indicated the formation of mineral carbon and multilayer graphene. 
Further experiments are needed to optimize the affecting factor quantities and to explore other additives introduced into the mixture which could improve pigment absorptivity.

\section{ACKNOWLEDGMENT}

Abengoa Solar S.A. for providing the necessary resources to conduct this research.

\section{FUNDING}

Abengoa Solar S.A.

\section{NOMENCLATURE}

$\begin{array}{ll}C P B & \text { Cetylpyridinuim bromide hydrate (98\%) } \\ \text { POSS } & \text { PSS-Trisilanol-isooctyl substituted } \\ M & \text { Montmorillonite } \\ \text { GMC } & \text { Dultilayer-graphene-montmorillonite composites } \\ D o E & \text { Design of experiments } \\ \varepsilon \% & \text { Absorptance } \\ \alpha \% & \end{array}$




\section{REFERENCES}

[1] Ning, X., and Lovell, M. R., 2002, "On the Sliding Friction Characteristics of Unidirectional Continuous FRP Composites," ASME Journal of Tribology, 124(1), pp. 513. DOI: $10.1115 / 1.40224567$

[2] Barnes, M., 2001, "Stresses in Solenoids," J. Appl. Phys., 48(5), pp. 2000-2008. DOI: $10.1115 / 1.40224567$

[3] Jones, J., 2000, Contact Mechanics, Cambridge University Press, Cambridge, UK, Chap. 6. ISBN: 978-3-16-148410-0

[4] Lee, Y., Korpela, S. A., and Horne, R. N., 1982, "Structure of Multi-Cellular Natural Convection in a Tall Vertical Annulus," Proc. 7th International Heat Transfer Conference, U. Grigul et al., eds., Hemisphere, Washington, DC, 2, pp. 221-226.

[5] Hashish, M., 2000, "600 MPa Waterjet Technology Development," High Pressure Technology, PVP-Vol. 406, pp. 135-140.

[6] Watson, D. W., 1997, "Thermodynamic Analysis," ASME Paper No. 97-GT-288.

[7] Tung, C. Y., 1982, "Evaporative Heat Transfer in the Contact Line of a Mixture," Ph.D. thesis, Rensselaer Polytechnic Institute, Troy, NY.

[8] Kwon, O. K., and Pletcher, R. H., 1981, "Prediction of the Incompressible Flow Over A Rearward-Facing Step," Technical Report No. HTL-26, CFD-4, lowa State Univ., Ames, IA.

[9] Smith, R., 2002, "Conformal Lubricated Contact of Cylindrical Surfaces Involved in a Non-Steady Motion," Ph.D. thesis, http://www.cas.phys.unm.edu/rsmith/homepage.html

[10] Bi, D., Li, Q., Chen, G.X., 2014, "Synthesis of polyhedral oligomeric silsesquioxanemodified organic montmorillonites and their nanocomposites with poly(l-lactide)", Applied Clay Science, 87, pp.34-39.

[11] Bakandritsos, A., Steriotis, T., Petridis, D., 2004, "High Surface Area Montmorillonite-Carbon Composites and Derived Carbons", Chemistry of Materials, 16, pp. 1551-1559.

[12] Galimberti M., Cipolletti V., Coombs M. 2013, Chapter 4.4 "applications of claypolymer nanocomposites", Dev, Clay Sci, 5 pp.539-586. 
[13] Perrin, F.X., Bruzaud, S., Grohens, Y.,2013, "Structure and thermal behaviour of polyhedral oligomeric silsesquioxane modified montmorillonite", Applied Clay Science, 49 pp. 113-119.

[14] Jerman, I., Koželj, M., Orel, B. 2010, "The effect of polyhedral oligomeric silsesquioxane dispersant and low surface energy additives on spectrally selective paint coatings with self-cleaning properties", Solar Energy Materials and Solar Cells, 94 pp. 232-245.

[15] Meyers, C.J., Shah, S.D., Patel, S.C., Sneeringer, R.M., Bessel, C.A., Dollahon, N.R. , Leising, R.A., Takeuchi, E.S., 2001, "Templated synthesis of carbon materials from zeolites ( $\mathrm{Y}$, beta, and ZSM-5) and a montmorillonite clay (K10): Physical and electrochemical characterization", The Journal of Physical Chemistry B, 105, pp. 2143 2152.

[16] Pinnavaia, T.J., 1983, “Intercalated clay catalysts”, Science, 220, pp. 365-371.

[17] Sonobe, N., Kyotani, T., Tomita, A., 1990, "Carbonization of polyfurfuryl alcohol and polyvinyl acetate between the lamellae of montmorillonite", Carbon, 28, pp. 483488.

[18] Zhao, F., Wan, C., Bao, X., Kandasubramanian, B., 2009 “Modification of montmorillonite with aminopropylisooctyl polyhedral oligomeric silsequioxane", Journal of Colloid and Interface Science, 333 pp. 164-170.

[19] Zhu, H., Vansant, E., Lu, G., 1999, “Development of composite adsorbents of carbon and intercalated clay for $\mathrm{N} 2$ and $\mathrm{O} 2$ adsorption: a preliminary study", Journal of colloid and interface science, 210, pp. 352-359.

[20] Liu, T., Li, Y., Du, Q., Sun, J., Jiao, Y., Yang, G., Wang, Z., Xia, Y., Zhang, W., Wang, K., 2012, "Adsorption of methylene blue from aqueous solution by graphene, Colloids and Surfaces B" Biointerfaces, 90, pp. 197-203.

[21] Akhavan, O., 2010, "The effect of heat treatment on formation of graphene thin films from graphene oxide nanosheets", Carbon, 48, pp. 509-519.

[22] Ferrari, A., Meyer, J., Scardaci, V., Casiraghi, C., Lazzeri, M., Mauri, F., Piscanec, S., Jiang, D., Novoselov, K., Roth, S., 2006, "The Raman fingerprint of graphene layers", Phys. Rev. Lett. 97, 187401.

[23] Bandosz, T.J., Jagiello, J., Putyera, K., Schwarz, J.A. 1996, “Pore structure of carbonmineral nanocomposites and derived carbons obtained by template carbonization", Chemistry of materials, 8, pp. 2023-2029. 


\section{Figure Captions List}

Fig. 1 Initial coating samples prepared from the synthesized pigments

Fig. 2 Means plot for absorbance response (Abs\%) with the sugar levels; (1)2:1, (2)-1:1, (3)-0.5:1 (left) and with the Modifier levels: 1-CPB, 2-POSS, 3CPB and POSS together (right)

Fig. 3 Composite material designed as ideal black pigment production scheme with the selected raw materials

Fig. 4 Interactions plot for initial absorptivity response (left), after $24 \mathrm{~h}$ at $600 \mathrm{O} \mathrm{C}$ (center) and after $24 \mathrm{~h}$ at $700^{\circ} \mathrm{C}$ (right). Sugar concentration ratio; (1)-2:1, (2)-1:1, (3)-0.5:1. Modifier levels: (1)-CPB, (2)-POSS, (3)-CPB and POSS together

Fig. 5 Interactions plot for adhesion response after $24 \mathrm{~h}$ at $600^{\circ} \mathrm{C}$ (left) and after $24 \mathrm{~h}$ at $700^{\circ} \mathrm{C}$ (right). Sugar levels; (1)-2:1, (2)-1:1, (3)-0.5:1. Modifier levels: (1)-CPB, (2)-POSS, and (3)-CPB and POSS together

Fig. 6 TEM images for C1_6 (left) and C1_8 (right) samples

Fig. $7 \quad$ X-ray diffraction pattern of GMC samples at different synthesis conditions and original montmorillonite (M), and calcined montmorillonite (M_T800)

Fig.8 Raman shift for the same sugar-nanoclay content in the synthesis process $\operatorname{MAz}(1: 1)$ 


\section{Table Caption List}

Table 1 DoE $3^{2}$ for the evaluation of montmorillonite pigment properties, depending on sugar concentration and presence of modifiers

Table 2 Absorptance $(\alpha \%)$ and emittance $(\varepsilon \%)$ of the initial synthesized coating samples and after thermal tests. - No available result because of problems with handling samples

Table 3 Analysis of variance (ANOVA) to maximize the initial absorbance response $\alpha \%$ using three experiment replications (BLOCK). ${ }^{\text {a }}$ degrees of freedom

Table 4 Adherence results from the Scratch-proof of the initial samples and after the thermal tests

Table 5 DoE results balance for the absorption and adherence GMC properties 